\title{
Retrospective Analysis of the Outcomes in Orbital Floor Fractures: Guidelines for Better Strategic Management
}

\author{
HOSSAM ELGAYAR, M.Sc.*; OMAR OSAMA SHOUMAN, M.D.*; MOSTAFA M. ABDELHALIM, M.D.*; \\ ASHRAF ABASS, M.D.** and AHMED M. ZEINA, M.D.*
}

The Department of Plastic Surgery* and General Surgery Department**, Faculty of Medicine, Mansoura University

\begin{abstract}
Aim: Orbital trauma is considered one of the most common maxillofacial traumas with functional and cosmetic impact to eye globe. The main objective is to establish a roadmap for the management of orbital floor fractures.

Patients and Methods: One hundred and seventy-three patients were selected from the database of Mansoura University Hospitals with orbital floor fractures who were treated at the Department of Plastic \& Reconstructive Surgery Department over past 4 years. Cases were retrospectively reviewed by preoperative clinical findings, management, surgical approaches, and sequelae. Authors evaluated timing and indication of surgical intervention, surgical outcomes, complications, and materials used for orbital reconstruction.

Results: In total, there were (173) cases of orbital fractures with average age of (23.14) years. The leading cause of these fractures was motor traffic accident (64.7\%). Pure blow-out fractures represent $25 \%$ of cases while fractures of inferior orbital rim alone were $45 \%$ of cases. Inferior orbital rim associated with orbital fractures were $30 \% .57 .2 \%$ of patients were managed surgically while $42.8 \%$ patients were managed conservatively. Conchal graft was used in 19 cases for floor reconstruction while 15 cases were managed by titanium mesh. In the follow-up, 10 patients still complain of enophthalmos, while 7 patients still complain of diplopia.

Conclusions: Better postoperative results were presented in cases managed immediately or within two weeks surgically, A guideline for choice of effective protocol for management was developed.
\end{abstract}

Key Words: Diplopia - Enophthalmos - Inferior orbital wall - Infraorbital paranesthesia - Orbital floor fracture - Ocular motility disorders.

\section{INTRODUCTION}

Orbital trauma is considered one of the most common maxillofacial traumas with surgical importance as it is related to eye globe, so, it may affect ocular motility and visual acuity. Up to $70 \%$ of orbital fractures are associated with injuries of eye globe and zygomatico-maxillary fractures [1]. Eighty percent of orbital fractures causes are due to road traffic accidents, sport activities and assault [2]. Fractures of the bony orbit may occur alone or as a part of complex facial fractures. Isolated fractures of the floor may occur without associated fracture of orbital rim [3].

Orbital wall fractures are classified as isolated fractures, involving a single orbital wall, or as combined fractures, when more than one orbital wall is involved. The floor is the most common fracture of the four walls because it lies on the maxillary sinus which act as a dead space also there is no support for the floor [4]. Orbital floor fractures can be classified as pure or impure blowout fractures; the pure fractures are isolated orbital floor fractures, while the impure are also associated with orbital rim fracture involving other contiguous bones (maxillary, zygomatic, naso-ethmoidal, or frontal) [5].

These fractures may cause significant functional and cosmetic complications, such as hypoesthesia or paresthesia through the infraorbital nerve, diplopia, enophthalmos, limited ocular motility especially upward movement, and ocular injuries which may affect visual acuity [6].

In the literature, there are several discordant studies regarding the epidemiological, clinical, and demographic characteristics of patients, type of surgical approach, implant materials, and surgical timing when it comes to orbital floor fractures. From both epidemiological and care viewpoints, there are discrepancies between global series regarding conservative or surgical treatment [7].

Authors retrospectively review clinical and epidemiological findings, surgical techniques, surgical outcomes, association between type of surgical approaches and materials used for reconstruction and complications. The objectives were to review and evaluate indications for surgery, surgical approaches, and the selection of reconstructive materials for managing orbital floor de- 
fects. Finally, various treatments used and their connection to sequelae found in patients were studied to establish effective roadmap for good strategy management.

\section{PATIENTS AND METHODS}

One hundred seventy-three patients with orbital floor fractures, either isolated or as part of orbital or midface fractures, were included in this study. All patients underwent treatment at the Department of Plastic \& Reconstructive Surgery, Mansoura University. The patient's data were extracted from hospital records between January 2016 and December 2020. The study was approved by the Ethical Committee of Faculty of Medicine (MS.19.06.705).

The patients were retrospectively analyzed for gender, age, mode of trauma, classification of fracture, preoperative symptoms, conservative or surgical treatment, timing of surgical intervention, surgical approaches, materials used for reconstruction and postoperative complications. Diagnosis was based on clinical presentation and computed tomography (CT) scans of the orbit in both axial and coronal view. All patients were ophthalmologically examined for assessment of any problem in visual acuity, any change in pupil size and ocular motility on the day of admittance, preoperatively, postoperatively, and during follow-up in cases with complications.
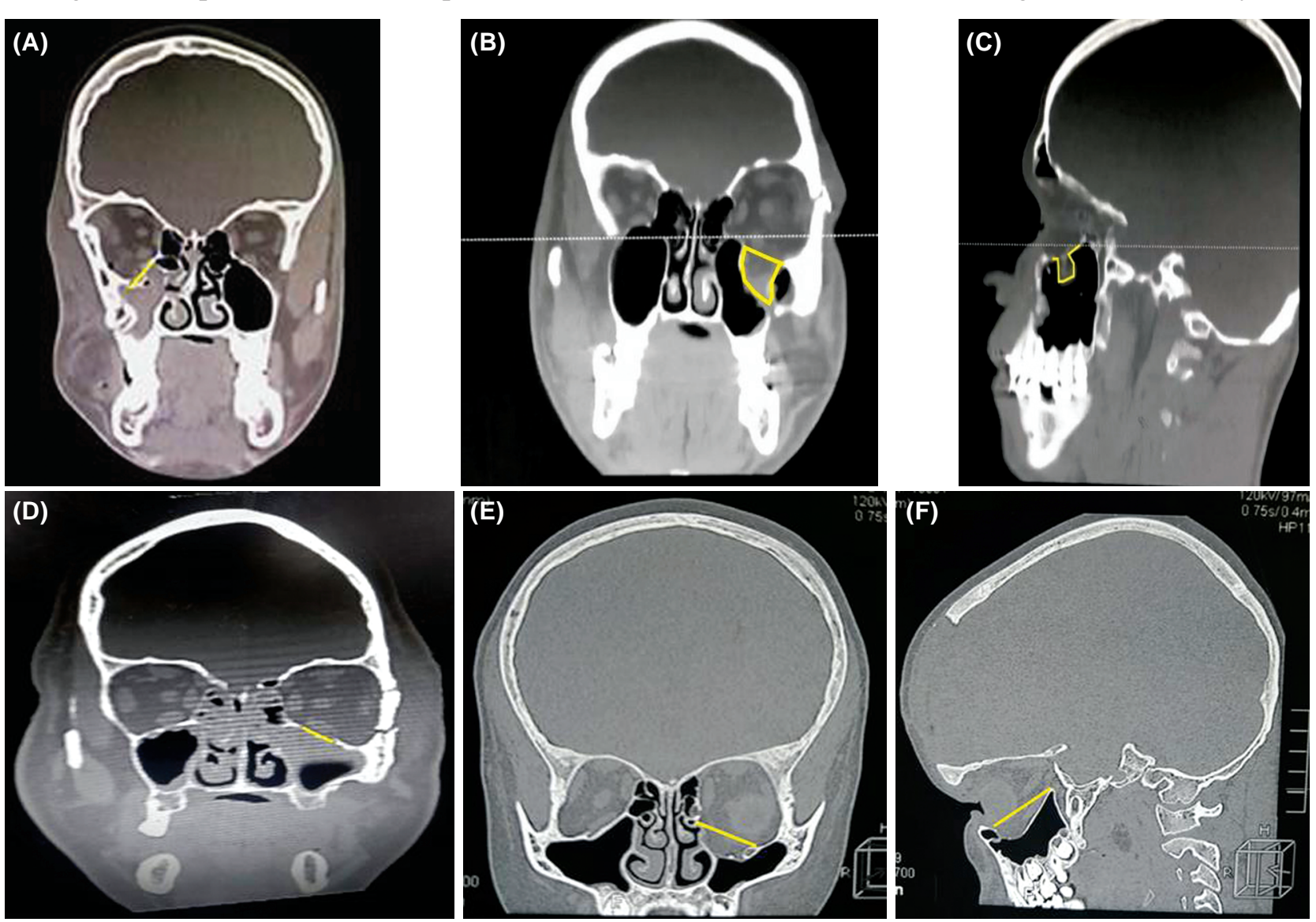

Fig. (1): CT scan of facial bones showing different herniation volumes in cases with orbital floor fractures.
Management of cases was dependent on presentation by clinical examinations, type of fractures and volume of orbital soft tissue herniation by CT scan at the time of their injury. The CT scan used 2-mm slices, the defect size and the volume of herniation were measured using both axial and coronal sections of the herniated orbital content. The computerized three-dimensional (3D) added software in the device (Planmeca, Romexis software version 6), it converts it to $3 \mathrm{D}$ model for measuring the herniated soft tissue volume. The herniated orbital soft tissue was defined as the displaced orbital content, including orbital fat and muscle, herniating through the fracture of the orbital floor into the maxillary sinus.

Some cases were managed by conservative measures and other cases had reconstructive surgeries. Indications for surgery were determined by the presence of symptoms, such as diplopia, enophthalmos, ocular motility disturbance, infraorbital bony stepping, orbital deformity, as well as orbital soft tissue herniation in the CT scan (Fig. 1). Patients with medical instability, retinal tear, globe perforation and intensive care admission were delayed for surgical repair. Patients without orbital rim step deformity, or orbital soft tissue herniation, also without muscular entrapment or enophthalmos more than $2 \mathrm{ml}$ were managed conservatively. 
Three different surgical approaches for orbital reconstruction were used; subciliary, transconjunctival, and existing wound incisional approach (Fig. 2). All operations were done by plastic surgeons. Open reduction and fixation by miniplates to restore bony stability for cases without soft tissue herniation on terms of presentation and imaging studies and verified intraoperatively. Forced duction test was done for all surgically managed cases intraoperatively to confirm no longer muscular entrapment and full movement of eye globe in all directions.

For orbital floor reconstruction, titanium mesh and conchal cartilage graft were used in large orbital floor defects $\left(>2 \mathrm{~cm}^{2}\right)$ (Fig. 3). The sequalae remained after surgery and conservative care was recorded and patients followed by clinical data and CT scan data up to one year.

Data entry and statistical analyses were performed using SPSS (statistical package of social sciences) version 20.0 (SPSS Inc., Chicago, IL, USA). Categorical variables were compared using Chi square test. In addition, Kruskal Wallis test (z) was used to compare non-parametric continuous clinical variables in three different groups. $p$-value $<0.05$ was considered as statistically significant.
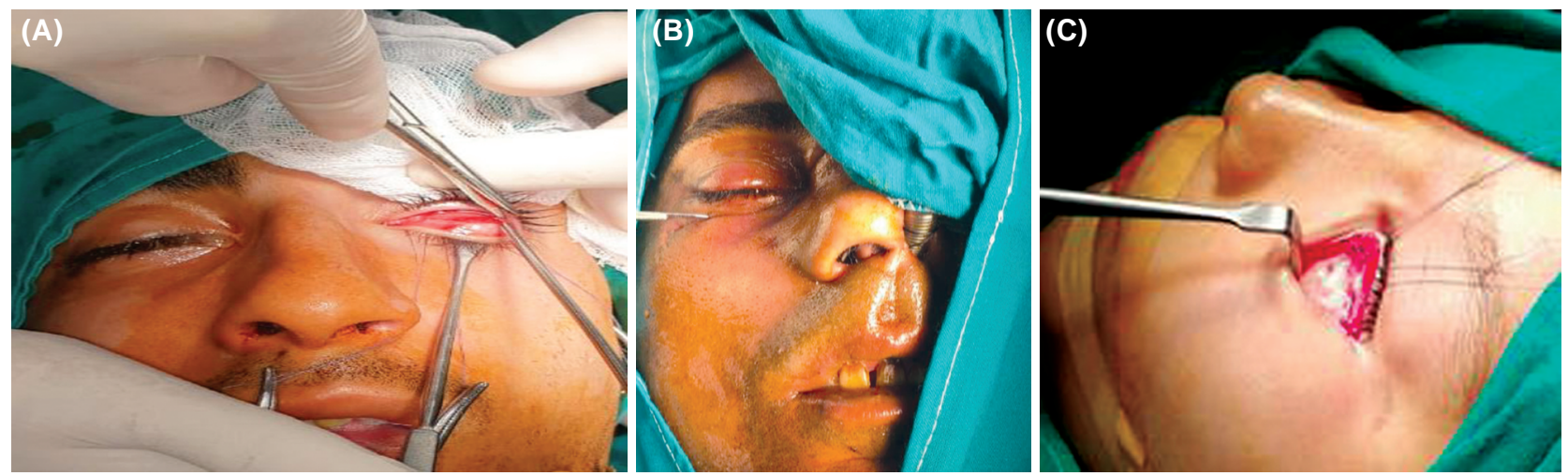

Fig. (2): Different surgical approaches for orbital floor fractures. (A) Transconjunctival incision. (B) Existing wound incision. (C) Subciliary incision.

(A)

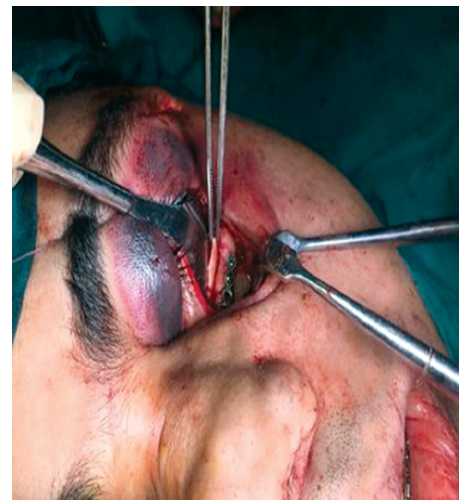

(C)

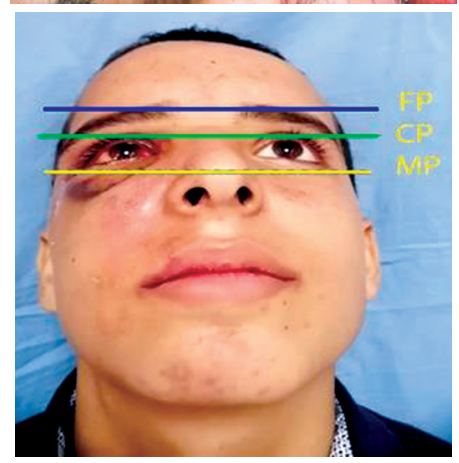

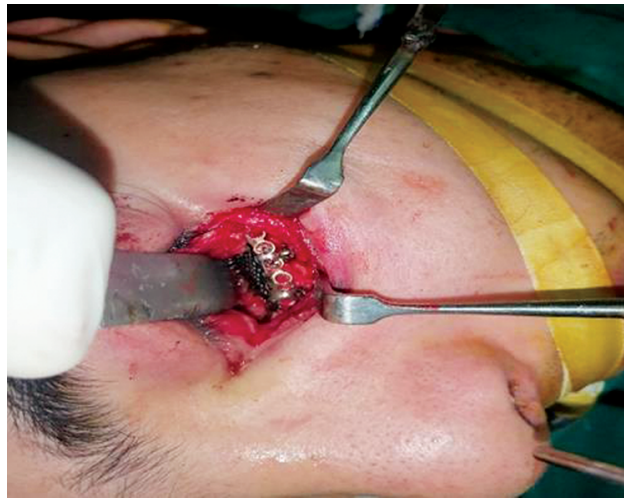

(B)

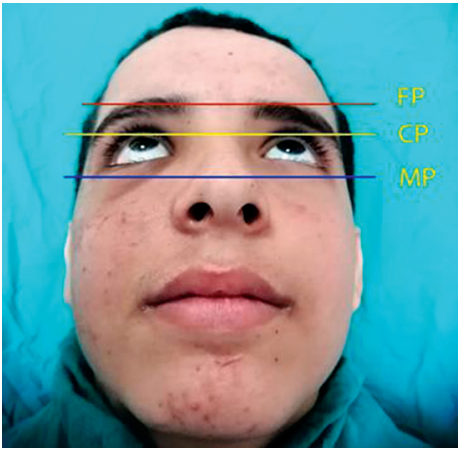

(D)

Fig. (3): Orbital floor reconstruction. (A) Reconstruction with conchal cartilage graft. (B) Reconstruction with titanium mesh. (C) Preoperative clinical inferior view showing enophthalmos right eye (The photographs are taken at a standardized angle of head tilt, for example placing the tragus of the ear and the projection of the chin in a line parallel to the floor; assessment of the anterior corneal projection (CP), compared to the frontal process projection (FP) and the maxillary process projection (MP). (D) Clinical inferior view after 6 months showing resolved enophthalmos. 


\section{RESULTS}

Study included 173 cases. Males accounted for $84 \%$ of cases $(n=153)$, while females accounted for $16 \%(n=20)$. Mean age of the included cases was 23.14 years. Twenty five percent of cases (43/173) presented with pure orbital floor fractures, while fractures of inferior orbital wall alone were $45 \%$ of all cases (78/173). Inferior orbital wall associated with orbital fractures were $30 \%$ of all cases (52/173). Orbital wall fractures were associated with orbital floor fractures in $36.4 \%$ of all cases (63/173). Other maxillofacial fractures as

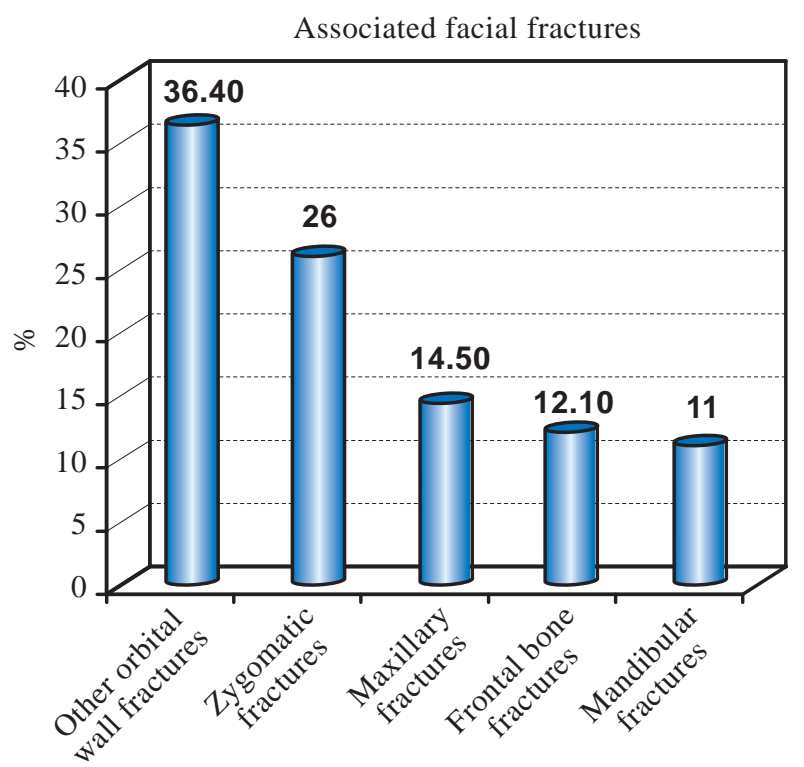

Fig. (4): Incidence of facial fractures associated with orbital fractures.

The average postoperative hospitalization duration was 3 days till edema was relieved and postoperative ophthalmological examination was performed for visual acuity and ocular motility, the follow-up period was 8.2 months ( 6 months to 1 year). Ninety-nine patients were managed surgically $(57.2 \%)$, while 74 patients $(42.8 \%)$ were managed conservatively. Sixty-five patients $(37.5 \%)$ were surgically repaired by open reduction and fixation using titanium plates and screws in cases had inferior orbital wall fractures with herniation volume less than $1 \mathrm{ml}^{3}$ without significant enophthalmos and diplopia. Conchal graft was used to reconstruct orbital floor defect in 11\% (19 cases) while $8.7 \%$ (15 cases) were managed by titanium mesh.

In surgically managed cases (Table 1 ), enophthalmos was the most common sign (44.4\%). Enophthalmos improved in $38.6 \%$ postoperatively while $7.1 \%$ still complain of enophthalmos (Fig. zygomatic fractures were $26 \%$ (45/173), maxillary fractures were $14.5 \%$ (25/173), frontal bone fractures were $12.1 \%(21 / 173)$ and mandibular fractures were $11 \%$ (19/173) (Fig. 4).

Among the multiple causes of the orbital floor fractures in our study, road traffic accidents (RTA) (car and motorcycle) were the most frequent in $64.7 \%(112 / 173)$ of cases. Falling from height (FFH) came in the second place with $23.1 \%$ (40/173) of cases. Violence was the third common cause with $12.2 \%$ (21/173) of cases (Fig. 5).

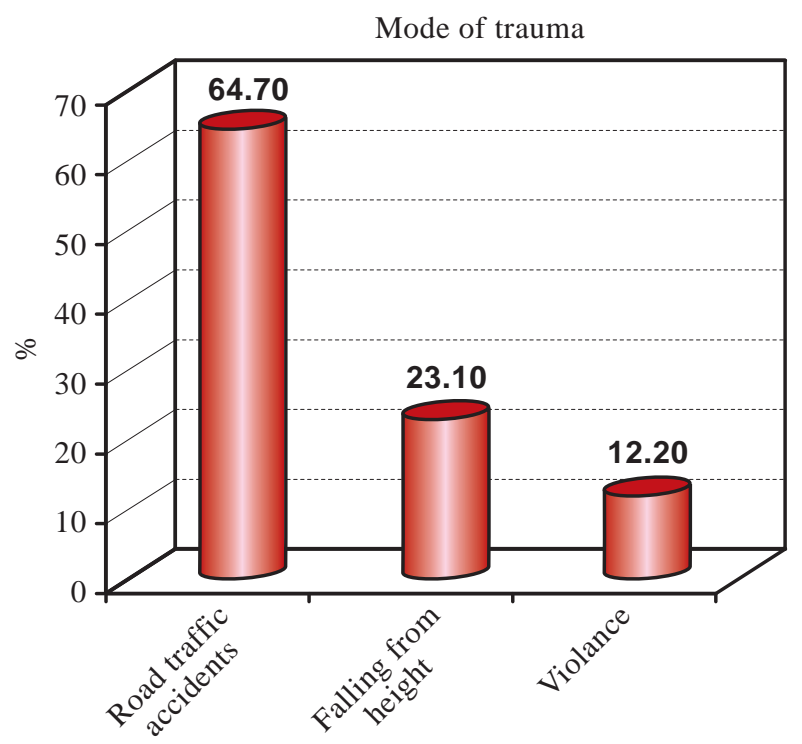

Fig. (5): Mode of trauma.

3C,D). Diplopia was a complaint in $42.4 \%$ of patients, postoperatively $6.1 \%$ of patients were still complain of diplopia. The third common complaint was limited ocular motility in different directions was observed in $(41.4 \%)$ divided as following (upward limited ocular motility in $(23.2 \%)$ - limited adduction in $(6.1 \%)$ - limited abduction in $(12.1 \%)$. Postoperatively $3 \%$ of patients still had minimal degree of limited ocular motility but without affection of visual acuity. The fourth common complaint was infraorbital hypoesthesia $(39.4 \%)$.

According to the non-surgically managed patients (Table 1), enophthalmos was observed in 31 patients (41.9\%). Diplopia was the second common sign $(35.1 \%)$. In contrast to the surgically managed cases, infraorbital hypoesthesia was the third common manifestation $(24.3 \%)$ while limited ocular motility in different directions was observed in 4 patients $(5.4 \%)$. 


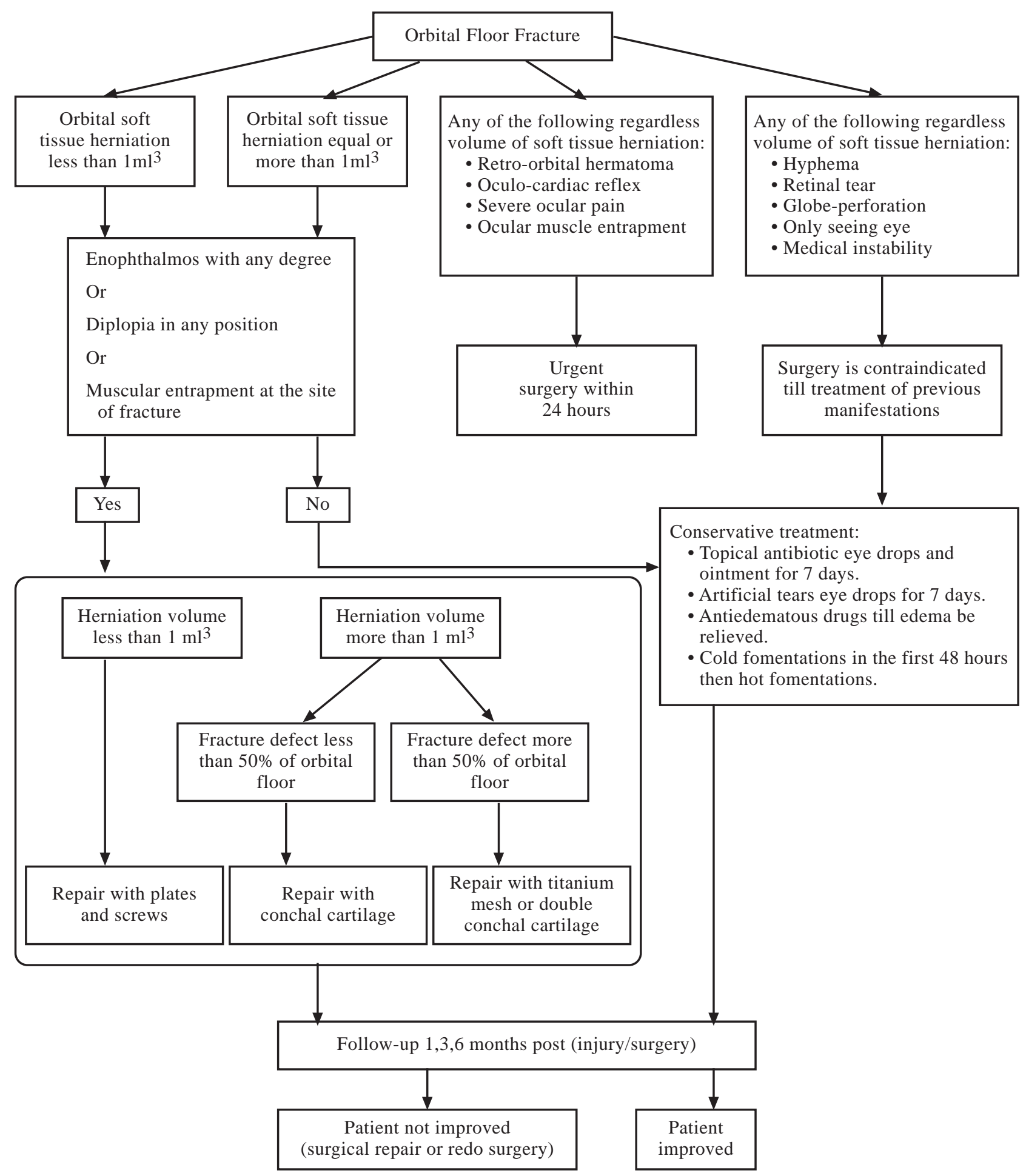

Fig. (6): Algorithm for management of orbital floor fractures.

Titanium mesh was used in 15 patients while conchal graft used in 19 patients (Table 2). In patients managed by titanium mesh; the most common signs were enophthalmos $(66.7 \%)$, limited upward ocular motility (66.7\%), preoperative diplopia (60\%), infraorbital hypoesthesia $(33.3 \%)$, and limited abduction (13.3\%). In patients managed by conchal graft; $47.4 \%$ of patients had enophthalmos, $36.8 \%$ with preoperative diplopia, $42.1 \%$ complaining of infraorbital hypoesthesia, $42.1 \%$ had limited upward ocular motility, 4 patients $(21.1 \%)$ with limited abduction and 4 patients $(21.1 \%)$ with limited adduction. 
Three types of surgical incisions were used (Table 3). The subciliary incision was used in 60 patients $(60.6 \%)$, while wound incision was used in 29 patients $(29.3 \%$ ) who had already wound at lower eyelid. Transconjunctival incision was used in 10 patients $(10.1 \%)$.

Three different times had been used for repair according to time of patient admission either recent or delayed (Table 4). Immediate repair was done

Table (1): Surgical versus non-surgical management.

\begin{tabular}{|c|c|c|c|}
\hline & $\begin{array}{c}\text { Surgical } \\
\mathrm{N}=99\end{array}$ & $\begin{array}{c}\text { Non-surgical } \\
N=74\end{array}$ & $\begin{array}{c}p- \\
\text { value }\end{array}$ \\
\hline \multicolumn{4}{|l|}{ Complaint: } \\
\hline Enophthalmos & $44(44.4 \%)$ & $31(41.9 \%)$ & 0.7 \\
\hline Diplopia & $42(42.4 \%)$ & $26(35.1 \%)$ & 0.3 \\
\hline Infraorbital hypoesthesia & $39(39.4 \%)$ & $18(24.3 \%)$ & $0.02 *$ \\
\hline \multicolumn{4}{|l|}{ Limited ocular motility: } \\
\hline Adduction & $6(6.1 \%)$ & $0(0 \%)$ & $<0.001 *$ \\
\hline Abduction & $12(12.1 \%)$ & $3(4.1 \%)$ & \\
\hline \multirow[t]{2}{*}{ Upward } & $23(23.2 \%)$ & $1(1.4 \%)$ & \\
\hline & Postoperative & Follow-up & \\
\hline \multicolumn{4}{|l|}{ Enophthalmos: } \\
\hline Improved & $36(36.4 \%)$ & $28(37.8 \%)$ & 0.9 \\
\hline Not improved & $7(7.1 \%)$ & $3(4.1 \%)$ & \\
\hline \multicolumn{4}{|l|}{ Diplopia: } \\
\hline Improved & $38(38.6 \%)$ & $23(31.1 \%)$ & 0.5 \\
\hline Not improved & $4(6.1 \%)$ & $3(4.1 \%)$ & \\
\hline \multicolumn{4}{|l|}{ Infraorbital hypoesthesia: } \\
\hline Improved & $35(35.4 \%)$ & $17(23 \%)$ & $0.03 *$ \\
\hline Not improved & $4(4 \%)$ & $1(1.4 \%)$ & \\
\hline \multicolumn{4}{|l|}{ Limited ocular motility: } \\
\hline Improved & $38(38.4 \%)$ & $4(5.4 \%)$ & $<0.001 *$ \\
\hline
\end{tabular}

in 5 cases complaining of urgent manifestation as sever diplopia, severe enophthalmos, optic nerve compression or retroorbital hemorrhage. Repair within two weeks was done in most cases (57 patients). Delayed repair was done in 37 cases. Table (4) analyses different presentation and methods surgical intervention according to time of repair. Postoperative sequalae were retrospectively analyzed and expressed in all Tables (1-4).

Table (2): Comparison between titanium mesh \& conchal graft.

\begin{tabular}{|c|c|c|c|}
\hline & $\begin{array}{l}\text { Titanium mesh } \\
\qquad N=15\end{array}$ & $\begin{array}{l}\text { Conchal graft } \\
\mathrm{N}=19\end{array}$ & $\begin{array}{c}p- \\
\text { value }\end{array}$ \\
\hline \multicolumn{4}{|l|}{ Preoperative: } \\
\hline Enophthalmos & $10(66.7 \%)$ & $9(47.4 \%)$ & 0.2 \\
\hline Diplopia & $9(60 \%)$ & $7(36.8 \%)$ & 0.1 \\
\hline Infraorbital hypoesthesia & $5(33.3 \%)$ & $8(42.1 \%)$ & 0.6 \\
\hline \multicolumn{4}{|l|}{ Limited ocular motility: } \\
\hline Adduction & $0(0 \%)$ & $4(21.1 \%)$ & 0.3 \\
\hline Abduction & $2(13.3 \%)$ & $4(21.1 \%)$ & \\
\hline Upward & $10(66.7 \%)$ & $8(42.1 \%)$ & \\
\hline \multicolumn{4}{|l|}{ Postoperative: } \\
\hline \multicolumn{4}{|l|}{ Enophthalmos: } \\
\hline Improved & $10(66.7 \%)$ & $7(36.8 \%)$ & 0.1 \\
\hline Not improved & $0(0 \%)$ & $2(10.5 \%)$ & \\
\hline \multicolumn{4}{|l|}{ Diplopia: } \\
\hline Improved & $7(46.7 \%)$ & $4(21.1 \%)$ & 0.4 \\
\hline Not improved & $2(13.3 \%)$ & $3(15.8 \%)$ & \\
\hline \multicolumn{4}{|l|}{ Infraorbital hypoesthesia: } \\
\hline Improved & $4(26.7 \%)$ & $5(26.3 \%)$ & 0.6 \\
\hline Not improved & $1(6.7 \%)$ & $3(15.8 \%)$ & \\
\hline Limited ocular motility & $12(80 \%)$ & $16(84.2 \%)$ & $0.01 *$ \\
\hline
\end{tabular}

Table (3): Methods of surgical approaches (subciliary-transconjunctival-existing wound incision).

\begin{tabular}{|c|c|c|c|c|}
\hline & $\begin{array}{l}\text { Subciliary } \\
\text { approach } \\
\mathrm{N}=60\end{array}$ & $\begin{array}{l}\text { Transconjunctival } \\
\mathrm{N}=10\end{array}$ & $\begin{array}{l}\text { Existing Wound } \\
\text { incision } \\
\mathrm{N}=29\end{array}$ & $\begin{array}{c}p- \\
\text { value }\end{array}$ \\
\hline \multicolumn{5}{|l|}{ Age in years: } \\
\hline Mean(s) & $21.3(12.5 \%)$ & $28.7(10.5 \%)$ & $28.5(20.3 \%)$ & \multirow{3}{*}{$0.02 *$} \\
\hline Median & 20 & 28 & 25 & \\
\hline Min-max & $3-60$ & $16-50$ & $5-76$ & \\
\hline \multicolumn{5}{|l|}{ Sex: } \\
\hline Male & $51(85 \%)$ & $8(80 \%)$ & $23(79.3 \%)$ & \multirow[t]{2}{*}{0.3} \\
\hline Female & $9(15 \%)$ & $2(20 \%)$ & $6(20.7 \%)$ & \\
\hline \multicolumn{5}{|l|}{ Mode of trauma: } \\
\hline FFH & $4(6.7 \%)$ & $0(0 \%)$ & $2(6.9 \%)$ & \multirow[t]{3}{*}{0.3} \\
\hline RTA & $46(76.7 \%)$ & $8(80 \%)$ & $23(79.3 \%)$ & \\
\hline Struggle & $10(11.7 \%)$ & $2(20 \%)$ & $4(13.8 \%)$ & \\
\hline \multicolumn{5}{|l|}{ Complications: } \\
\hline Entropion & 0 & $1(10 \%)$ & 0 & \multirow[t]{4}{*}{$<0.001 *$} \\
\hline Ectropion & $8(13.3 \%)$ & $0(0)$ & $8(13.3 \%)$ & \\
\hline Plate infection & $1(1.7 \%)$ & $0(0)$ & $3(10.3 \%)$ & \\
\hline Visible scar & $3(5 \%)$ & $0(0)$ & $18(62.1 \%)$ & \\
\hline
\end{tabular}

N: Number of cases.

\# Kruskalwallis test.

RTA: Road traffic accidents.

$* p$-value is considered statistically significant $<0.05$. 
Table (4): Different methods of surgical intervention according to time of repair.

\begin{tabular}{|c|c|c|c|c|}
\hline & $\begin{array}{l}\text { Immediate repair } \\
\qquad(\mathrm{N}=5)\end{array}$ & $\begin{array}{l}\text { Within two weeks } \\
\qquad(\mathrm{N}=57)\end{array}$ & $\begin{array}{l}\text { Delayed } \\
(\mathrm{N}=37)\end{array}$ & $\begin{array}{c}p- \\
\text { value }\end{array}$ \\
\hline \multicolumn{5}{|l|}{ Age: } \\
\hline Mean(s) & $16.4(5.8 \%)$ & $26.2(17.5 \%)$ & $23.1(12.4 \%)$ & \multirow{3}{*}{0.1} \\
\hline Median & 17.5 & 24 & 26 & \\
\hline Min-max & $8-23$ & $3-76$ & $5-50$ & \\
\hline \multicolumn{5}{|l|}{ Sex: } \\
\hline Male & $7(87.5 \%)$ & $49(86 \%)$ & $31(83.8 \%)$ & \multirow[t]{2}{*}{0.6} \\
\hline Female & $1(12.5 \%)$ & $8(14 \%)$ & $6(16.2 \%)$ & \\
\hline \multicolumn{5}{|l|}{ Mode of trauma: } \\
\hline FFH & $0(0)$ & $6(10.5 \%)$ & $2(5.4 \%)$ & \multirow[t]{3}{*}{$<0.001 *$} \\
\hline RTA & $3(60 \%)$ & $37(64.9 \%)$ & $32(86.4 \%)$ & \\
\hline Struggle & $2(40 \%)$ & $14(24.6 \%)$ & $3(8.1 \%)$ & \\
\hline \multicolumn{5}{|l|}{ Preoperative: } \\
\hline Enophthalmos & $3(60 \%)$ & $29(50.9 \%)$ & $15(40.5 \%)$ & 0.5 \\
\hline Diplopia & $5(100 \%)$ & $23(40.4 \%)$ & $16(43.2 \%)$ & 0.3 \\
\hline Infraorbital hypoesthesia & $4(80 \%)$ & $27(47.4 \%)$ & $14(37.8 \%)$ & 0.07 \\
\hline \multicolumn{5}{|l|}{ Postoperative: } \\
\hline \multicolumn{5}{|l|}{ Enophthalmos: } \\
\hline Improved & $2(40 \%)$ & $24(42.1 \%)$ & $10(27 \%)$ & \multirow[t]{2}{*}{0.8} \\
\hline Not improved & $1(20 \%)$ & $5(8.8 \%)$ & $5(13.5 \%)$ & \\
\hline \multicolumn{5}{|l|}{ Diplopia: } \\
\hline Improved & $4(80 \%)$ & $21(36.8 \%)$ & $10(27 \%)$ & \multirow[t]{2}{*}{0.4} \\
\hline Not improved & $1(20 \%)$ & $2(3.5 \%)$ & $6(16.2 \%)$ & \\
\hline \multicolumn{5}{|l|}{ Infraorbital hypoesthesia: } \\
\hline Improved & $3(60 \%)$ & $22(38.6 \%)$ & $8(21.6 \%)$ & \multirow[t]{2}{*}{0.1} \\
\hline Not improved & $2(40 \%)$ & $5(8.8 \%)$ & $7(18.9 \%)$ & \\
\hline
\end{tabular}

\section{DISCUSSION}

Orbital injury is considered one of the common maxillofacial traumas with surgical significance. Management of the orbital floor fracture is aimed at restoring the original shape and volume of the orbit, repositioning its contents, and recovering ocular motility. Retrospective study was done for 173 patients with orbital floor fractures; 112 patients were admitted in the duration between 2016 - Dec 2018, and 61 patients in the duration between 2019 - Dec 2020.

Regarding sex, 153 (84\%) of cases were males while females represented by $20(16 \%)$ of cases. This supports the statistics of Bartoli [8] and Gosau [9] in their retrospective studies there were $72.1 \%$ and $78.3 \%$ of cases were men and $27.9 \%, 21.7 \%$ were females, respectively. thus, the gender distribution was 3.6 male : 1 female.

The age range of the included cases was between (minimum 2 years, maximum 76 years). The peak incidence emerges in the 2 nd decade. Adult patients (>18 years) represented 63\% (109/173). So, pediatric patients counted $37 \%$ (64/173). In a study conducted by Biesman, the average of age was 27.5 years [10]. In another study done by Beige, the patients had a mean age of 37 years (range 7-91 years) [11].

Road traffic accidents (RTA) (car and motorcycle) were the most frequent in $64.7 \%(112 / 173)$ of cases (Fig. 5). In contrast to study of Venugopal, the principal etiology of orbital floor fractures was violent assault (29.6\%), followed by traffic accidents $(25.1 \%)$ [12].

Impure orbital floor fractures were most frequent type (associated with inferior orbital wall) in $75 \%$ of all cases, while pure orbital floor fractures were $25 \%$ of cases. These results matched to Gosau et al., in his study there was $53.8 \%$ patients $(\mathrm{n}=102)$ had zygomatic fractures with orbital floor affection, and $26.6 \%(n=50)$ had complex midface fractures [9]. Most blowout fractures occur along the thin floor of the orbit. Less commonly, blowout fractures can occur along the medial wall and orbital roof [4].

Regarding management (57.2\%) of all cases with herniation volume more than $1 \mathrm{ml}^{3}$ were managed surgically. This could be explained with that cases with herniation volume more than $1 \mathrm{ml}^{3}$ complain of significant enophthalmos and diplopia which needed surgical repair. Considering surgi- 
cally managed cases, inferior orbital wall only repair was the most frequent, $37.5 \%$ of cases were surgically repaired by plates and screws for inferior orbital wall. This could be explained with that these fractures were not associated with floor defects and herniation volume was less than $1 \mathrm{ml}^{3}$ without significant enophthalmos and diplopia. This supported by other studies in literature [1315]. Patients with herniation volume more than $1 \mathrm{ml}^{3}$ with significant enophthalmos and diplopia were surgically repaired by conchal cartilage graft in 11 percent while 8.7 percent of cases were managed by titanium mesh. This could be explained with that titanium meshes are expensive for most of patients and not usually available, also conchal cartilage is available and inert without immune reaction [15].

There was significant difference regarding improvement of ocular motility and infraorbital hypoesthesia between surgically and non-surgically managed cases. Postoperatively, there were residual enophthalmos (less than $2 \mathrm{ml}$ ) and diplopia (upward gaze) in $7.1 \%, 6.1 \%$ consecutively. After 6 months follow-up; diplopia was resolved while two patients still had enophthalmos. Rosado P and de Vicente $\mathrm{JC}$ reported persistent enophthalmos in $(3.8 \%)$, and diplopia in (2.2\%) [16]. Follow-up in nonsurgically managed cases, residual enophthalmos was observed in 3 patients which improved within one year. Diplopia was improved in 23 patients after 6 months, 3 patients had residual diplopia. Residual infraorbital hypoesthesia in $5.4 \%$ after one year. Different authors have reported an overall frequency of diplopia and infra orbital hypoesthesia between 5\% and 37\% [17], but diplopia as a persisting symptom has been reported in 5\%-7\% of patients [18]. Beige and his colleagues in their study gave similar result in non-surgical managed cases [11].

Orbital muscle edema, inflammation, and emergency surgery have been shown to be a major cause postoperative persistence of diplopia or enophthalmos, in delayed cases of orbital trauma, it is difficult to reconstruct the original size of the orbit because of bone remodeling and scarring [19]. So, in case of manifestation such as diplopia, limited ocular mobility or enophthalmos; delay of surgery or conservative management is not acceptable, authors recommend early operative management.

Reconstruction of orbital floor and restoration of volume can be performed using various types of materials, either autologous as bone grafts, cartilage grafts, and fat graft or alloplastic as titanium mesh [20,21]. The most used material was titanium, has the highest tensile strength despite easily bending, and it is compatible with radiographic imaging with a low risk of infection [21,22]. There was significant difference regarding treatment of limited ocular motility by use of both titanium mesh and conchal graft. In current study (Table 2), enophthalmos was improved in all cases managed by titanium mesh while in patients managed by conchal graft, 2 patients still complaining enophthalmos, one had been reoperated after 6 months. This may be attributed to subsequent fibrosis and remodeling, also titanium mesh is better in large defects [23]. Conchal graft was used in orbital floor fracture with defect size less than $50 \%$ of orbital floor size while titanium mesh was used in cases with orbital floor fracture with defect size more than $50 \%$ of orbital floor size.

Study by Kruschewsky support our preference in using concha than mesh as it is available, easily shaped, inert with no reaction, rarely associated infection, less harmful to orbital soft tissues and due to low socioeconomic standard in many cases as it is a cheap material for reconstruction [24]. Also, hidden scar for auricular cartilage can be hidden with use of the posterior approach.

Several orbital floor repair approaches have been well defined in literature, the number of factors influencing the choice of one such as the preference of surgeon and patient, overlying wounds, and presence of sufficient skin creases [4]. Subciliary incision was the most common used incision. It was used in $60.6 \%$ of cases (60/99). However, Bartoli preferred using lower eyelid incision in 231 patients $(76.6 \%)$ which contradict our finding [8]. The subciliary incision can allow for an adequate operative view to restore the orbit and allow using a large graft, also the fracture site can be easily explored; compared with other cutaneous midtarsal or subtarsal approach, scarring in the lower eyelid may be a problem, but these scars are inconspicuous.

The most frequent complications were visible scar (21 patients) managed through wound existing incision, ectropion (11 patients) and plates infection (4 patients) (Table 3). Four patients with ectropion (two from subciliary approach, two from existing wound approach) underwent surgery after 4 months by surgical release with full thickness skin graft and Z-plasty technique. The others were conservatively managed by taping and skin massage.

About time of repair, most cases were managed within two weeks in $57.5 \%$ of cases. Immediate repair was done in 5 cases with manifestation of 
sever diplopia, optic nerve compression and retroorbital hemorrhage. These results matched with retrospective study by Gosau et al. [9] and Yano H et al. [25]. Delayed repair after two weeks was done for 37 cases in contrast to Yano $\mathrm{H}$ et al., more than 60 percent of patients with enophthalmos were carried out after 1 month. It was indicated for patients with unstable general conditions, admitted at ICU with low Glasgow coma score and patients with globe injury. Better results and lower operative duration ranged (from $52 \mathrm{~min}$ to $88 \mathrm{~min}$ ) were associated with cases managed within two weeks and cases immediately managed (Table 4).

A common facial injury is the orbital floor fracture, but complete consensus on its optimal management has not been achieved. Comparisons between titanium mesh vs conchal cartilage graft, comparison between surgically vs non-surgically managed cases, analyses of different incisions used for surgical approach, also analyses different times of surgical repair was illustrated to reach for treatment roadmap. One advantage of this study; it was the first study in our center; second, authors suggest an algorithm and guidelines for better strategic management of orbital floor fractures as illustrated in Fig. (6). Furthermore, one limitation of this study is the lack of consecutive data for longer periods to further establish objective treatment guidelines and statistical data based on complication rates.

\section{Conclusion:}

To conclude, the suggested guidelines are based on authors retrospective analyses in patients with orbital fractures over last 4 years. Management should be systematically approached and depend on careful history taking, careful local examination, keeping in mind examination of the associated maxillofacial trauma. Orbital floor fractures are common, and this have both medical and medicolegal implications and literature contains conflicting recommendations for the care of these patients.

Acknowledgement: We would like to thank scientific research office of Mansoura Faculty of Medicine for statistical analysis.

\section{Funding: None.}

Conflict of interest: The authors declare that they have no conflict of interest to disclose.

Informed consent: For this type of study formal consent is not required. The study approved by ethical committee of Institutional Review Board (IRB), Mansoura Faculty of Medicine (MS.19.06.705).

\section{REFERENCES}

1- Nagase D.Y., Courtemanche D.J. and Peters D.A.: Literature data suggest that up to $70 \%$. The Canadian Journal of Plastic Surgery, 14 (3): 167-171, 2006.

2- Chi M.J., Ku M., Shin K.H. and Baek S.: The major causes of orbital traumas. Ophthalmologica, 224 (3): 167-175, 2010.

3- Chang E.W. and Manolidis S.: Orbital floor fracture management. Facial Plast. Surg., 21 (3): 207-13, 2005.

4- Holmes S., Perry M., McQuillan J. and White S.: Orbital Fractures. In: Perry M., Holmes S. (eds) Atlas of Operative Maxillofacial Trauma Surgery. Springer, 359-439, 2014.

5- Park M.S, Kim Y.J., Kim H., Nam S.H. and Choi Y.W.: Prevalence of Diplopia and Extraocular Movement Limitation according to the Location of Isolated Pure Blowout Fractures. Arch. Plast. Surg., 39 (3): 204-8, 2012.

6- Piombino P., Iaconetta G., Ciccarelli R., Romeo A., Spinzia A. and Califano L.: Repair of orbital floor fractures: Our experience and new technical findings. Craniomaxillofac Trauma Reconstr., 3 (4): 217-222, 2010.

7- Catherine Z., Courvoisier D.S. and Scolozzi P.: Is the pure and impure distinction of orbital fractures clinically relevant with respect to ocular and periocular injuries? A retrospective study of 473 patients. Journal of Craniomaxillo-facial Surgery: Official Publication of the European Association for Cranio-maxillo-facial Surgery, 47: 1935-1942, 2019.

8- Bartoli D., Fadda M.T., Battisti A., Cassoni A., Pagnoni M., Riccardi E., Sanzi M. and Valentini V.: Retrospective analysis of 301 patients with orbital floor fracture. J. Craniomaxillofac. Surg., 43: 244-247, 2015.

9- Gosau M., Schöneich M., Draenert F.G., Ettl T., Driemel O. and Reichert T.: Retrospective analysis of orbital floor fractures-complications, outcome, and review of literature. Clin. Oral Investig., 15: 305-313, 2011.

10- Biesman B.S., Hornblass A., Lisman R. and Kazlas M.: Diplopia after surgical repair of orbital floor fractures. Ophthalmic Plast. Reconstr. Surg., 12 (1): 9-16; discussion 17, 1996.

11- Beigi B., Khandwala M. and Gupta D.: Management of pure orbital floor fractures: A proposed protocol to prevent unnecessary or early surgery. Orbit, 33 (5): 336-42, 2014.

12- Venugopal M.G., Sinha R., Menon P.S., Chattopadhyay P.K. and Roy Chowdhury S.K.: Fractures in the Maxillofacial Region: A Four Year Retrospective Study. Med. J. Armed Forces India, 66 (1): 14-7, 2010.

13- Safi A.F., Richter M.T., Rothamel D., Nickenig H.J., Scheer M., Zöller J. and Kreppel M.: Influence of the volume of soft tissue herniation on clinical symptoms of patients with orbital floor fractures. J. Craniomaxillofac. Surg., 44 (12): 1929-1934, 2016

14- Wu C.M., Chen Y.A., Liao H.T., Chen C.H., Pan C.H. and Chen C.T.: Surgical treatment of isolated zygomatic fracture: Outcome comparison between titanium plate and bioabsorbable plate. Asian J. Surg., 41: 370-376, 2018.

15- Wang S., Xiao J., Liu L., Lin Y., Li X., Tang W., Wang H., Long J., Zheng X. and Tian W.: Orbital floor reconstruction: A retrospective study of 21 cases. Oral Surg. 
Oral Med. Oral Pathol. Oral Radiol. Endod., 106: 324330, 2008.

16- Rosado P. and de Vicente J.C.: Retrospective analysis of 314 orbital fractures. Oral Surg. Oral Med. Oral Pathol. Oral Radiol., 113 (2): 168-71, 2012.

17- Folkestad L., Lindgren G., Möller C. and Granström G.: Diplopia in orbital fractures: A simple method to evaluate eye motility. Acta. Otolaryngol., 127 (2): 156-66, 2007.

18- Tadj A. and Kimble F.W.: Fractured zygomas. ANZ J. Surg., 73: 49-54, 2003.

19- Balaji S.M.: Residual diplopia in treated orbital bone fractures. Ann. Maxillofacial Surg., 3 (1): 40-45, 2013.

20- Mohamed E.N., Setta H.S. and El Shahat A.: Comparative study between conchal cartilage grafts and split rib grafts in the reconstruction of orbital floor fractures. The Egyptian Journal of Plastic and Reconstructive Surgery, 42: 273-277, 2018.

21- Ghareeb F.M., Amin M., Eissa A., Eissa W. and Tharwat A.: Differential Volumetric Orbital Restoration (DVOR) for Correction of Traumatic Ocular Malposition. Ann. Plast. Reconstr. Surg., 2 (2): 1017, 2018.

22- Düzgün S. and Sirkeci B.: Comparison of post-operative outcomes of graft materials used in reconstruction of blow-out fractures. Ulus Travma Acil Cerrahi Derg., 26: 538-544, 2020.

23- Avashia Y.J., Sastry A., Fan K.L., Mir H.S. and Thaller S.R.: Materials used for reconstruction after orbital floor fracture. Journal of Craniofacial Surgery, 23 (7): S49S55, 2012.

24- De Souza Kruschewsky 1., Novais T., Daltro C., Branco B.C., Lessa M., Kruschewsky M.B. and De mello-filho, F.V.: Fractured orbital wall reconstruction with an auricular cartilage graft or absorbable polyacid copolymer. J. Craniofac. Surg., 22: 1256-1259, 2011.

25- Yano H., Nakano M., Anraku K., Suzuki Y., Ishida H., Murakami R. and Hirano A.: A consecutive case review of orbital blowout fractures and recommendations for comprehensive management. Plast. Reconstr. Surg., 124 (2): 602-611, 2009. 